\title{
Early Vascular Ageing (EVA): Definitions and Clinical Applicability
}

\author{
Pedro G. Cunha ${ }^{\mathrm{a}, \mathrm{b}, \mathrm{c}, *}$, Pierre Boutouyrie $^{\mathrm{d}}$, Peter M. Nilsson $^{\mathrm{e}}$ and Stéphane Laurent ${ }^{\mathrm{d}}$
}

${ }^{a}$ Center for the Research and Treatment of Arterial Hypertension and Cardiovascular Risk, Internal Medicine Department, Hospital Senhora da Oliveira, Guimarães / Minho University. Portugal; ${ }^{b}$ Life and Health Science Research Institute (ICVS) and School of Medicine, University of Minho; ${ }^{c} I C V S / 3 B$ 's - PT Government Associate Laboratory, Braga/Guimarães, Portugal; ${ }^{d}$ Department of Pharmacology and INSERM U970, Assistance Publique Hôpitaux de Paris, Université Paris Descartes, Paris, France; ${ }^{e}$ Department of Clinical Sciences, Lund University, Skane University Hospital, Malmö, Sweden

\begin{tabular}{l} 
A R T I C L E H I S T O R Y \\
\hline Received: February 20, 2017 \\
Revised: March 30, 2017 \\
Accepted: April 03, 2017 \\
DOI: \\
10.2174/15734021 13666170413094319
\end{tabular}

\begin{abstract}
Arterial stiffness has been accumulating evidence as an intermediate cardiovascular endpoint. It has been established as an independent risk marker for cardiovascular disease, and reflects the dissociation between chronologic and biologic age of large arteries-attributing earlier the risk that a normal vascular ageing process had installed to occur several years later. The concept of Early Vascular Ageing (EVA) is developed to establish primordial prevention, identifying individuals whose ageing path has been accelerated either by inherent features, interaction with the environment or arterial exposure to several types of insults that evolve to medial layer morphological changes. Understanding the pathophysiology of vascular ageing, its consequences and therapeutic opportunities is therefore an advantage that could be translated in time of prevention and survival free of cardiovascular disease. As the EVA construct is advancing, new features appear as interesting to better translate it into clinical practice.
\end{abstract}

\section{INTRODUCTION}

Early Vascular Ageing (EVA) is an evolving concept [13 ] that has been growing around the accumulating evidence surrounding arterial stiffness as an intermediate end-point and an independent predictor of cardiovascular disease and cardiovascular as well as total mortality [4]. This construct (EVA) is elaborating on the core idea that it is possible to identify at an early stage subjects with signs of an unsuccessful vascular ageing. This unsuccessful ageing (accelerated ageing), if undetected otherwise, would lead those subjects into earlier development of cardiovascular disease (CVD) and irrecoverable residual risk in spite of therapeutic primary or secondary prevention measures undertaken, later in time.

The purpose of this overview is to: 1) briefly review key pathophysiologic concepts concerning vascular ageing and associated risk of development of cardiovascular disease, as

\footnotetext{
*Address correspondence to Pedro Guimarães Cunha, $\mathrm{MD}, \mathrm{PhD}$, at the Center for the Research and Treatment of Arterial Hypertension and Cardiovascular Risk. Serviço de Medicina Interna do Hospital de Guimarães, Centro Hospitalar do Alto Ave; Life and Health Science Research Institute (ICVS), Minho University. Rua dos Cutileiros, Creixomil, 4810, Guimarães, Portugal; Tel: +351-253540330 (extension 41952);

E-mail: pedrocunha@ecsaude.uminho.pt
}

well as the established value of pulse wave velocity (PWV), a direct measurement of arterial stiffness, as a valuable biomarker of cardiovascular risk; 2) discuss existing definitions of EVA and its premises; 3 ) propose the clinical applicability of the concept to specific target groups; 4) review existing records of the prevalence of EVA in order to gauge future directions concerning therapeutic intervention and research; and to finally 5) debate therapeutic implications for subjects with EVA.

\section{CHANGES IN THE ARTERIAL TREE IN HYPER- TENSION CONDITIONING PROGRESSION TO ARTERIAL STIFFNESS AND ITS COMPLICATIONS}

The process of arterial ageing begins during the human intra-uterine life. During this period, not only the uterine environment, but also the development of the fetus and its cardiovascular system are under the influence of maternal hormonal, socio-economical and health characteristics $[5,6]$. The extent of the success of ageing could intuitively be measured as the accumulated number of chronologic years that a subject survives without disease or disease induced limitations. Still, one must be aware that the process of normal vascular ageing can be accelerated by a combination of the exposure to different factors that insult the arterial wall and the time of exposure to these insulting factors [7]. Thus, 
biologically speaking, the arterial wall can in fact appear older than its chronological age, reflecting adaptive changes to repeated insults and exposing earlier the subjects to the risk of development of cardiovascular disease that they would be subjected only years later [8].

With advancing age, and especially after 30 years of life, large arteries progressively lose their elastic properties [9, 10]. The process of arterial stiffening is mainly due to changes in the medial layer of the arterial wall, altogether referred to as arteriosclerosis. The normal media is composed of elastin, collagen, vascular smooth muscle cells (VSMC) and a mucopolysaccharide matrix [11]. These components are distributed in different proportions as we move from central (elastic) to peripheral (muscular) arteries; with age, large arteries are characterized by: 1) a reduction of the elastin component and changes in the interaction of elastin lamellae; 2) an increase in collagen and mucopolysaccharide matrix; 3) a reduction of VSMC and an increase in VSMC stiffness; and 4) a decreased activity in proteolytic enzymes, reducing the vessel's remodeling process as intended $[11,12]$.

Changes in the medial layer occur normally with ageing, and are the result of an equilibrium established between 3 key mechanisms: 1) cyclic stress (reflecting the cardiac cycle and subsequent repeated changes in the arterial structure promoted by the incident and the retrograde flow and pressure waves); 2) the arterial wall's repair mechanisms that correct the injuries promoted by this mechanical/elastic stress (9), but also, the insults to the arterial wall provoked by different aggressors (excessive blood pressure, dyslipidemia, diabetes and its advanced glycation end (AGE) products, smoking, inflammation, oxidative-stress, endothelial dysfunction and so many others) [13-18]; at the extreme of the possibilities leading to stiffer arteries, are the acquired or inherited lack of effective repairing mechanisms of the arterial wall or hereditary conditions promoting vascular ageing $[6,19]$. All these conditions can lead to an acceleration of medial changes naturally observed with age, and hence, increased cardiovascular risk.

As the central arteries become stiffer, they maintain their conduit function, but progressively lose their buffering property, transmitting high energy pulsatility into the vascular bed of organs highly vascularized but prepared only to deal with a continuous flow of blood, like the brain and the kidney - promoting target organ damage through pulsatility energy transmission, especially when the proximal/distal large arteries mismatch is lost, in response to the premature ageing, thus stiffening, of large arteries [9, 11, 20-23].

Finally, and concurring to the pathophysiology of cardiovascular disease promoted by changes in the arterial wall, stiffer arteries transmit not only the forward, but also the reflected pressure waves with higher velocity, and eventually with greater magnitude [24]. This earlier reflection will superimpose on the cardiac after-load and increase central and peripheral blood pressures, increasing the pulsatile energy transmitted to target organ damage and reducing coronary perfusion (as the coronary flow should be assured by the reflecting wave later in the diastole) $[12,24]$.

\subsection{The Blood Pressure Paradox in its Relationship with Arterial Stiffness}

The main determinants of pulse wave velocity (PWV) are age and blood pressure [25-27]. In a paradoxical sense, and as demonstrated by preceding arguments, increasing arterial stiffness will promote augmented pulse wave reflection and concurrent blood pressure increase. Until recently, this would appear a cyclic event, with higher blood pressure increasing arterial stiffness, and the later promoting higher levels of blood pressure. New evidence has surfaced in longitudinal studies, showing that not only is arterial stiffness a predictor of future development of hypertension [28, 29], but also that PWV and peripheral blood pressure have divergent evolutions in time $[27,30]$ and according to gender, obviating a partial independence of these players, who must have other variables explaining their variance. This is an argument in favor of directly measuring arterial stiffness, instead of estimating it through blood pressure and age algorithms.

On one hand, one can find a link between arterial stiffness and other blood pressure characteristics that have an impact in cardiovascular mortality: blood pressure variability, heart rate variability and impaired baroreceptor function (causing orthostatic hypotension) [31]; on the other hand, several mechanisms have been associated to the accelerated development of arterial stiffness and (indirectly) of increased blood pressure: the metabolic syndrome, inflammation and neurohormonal disorders, all inducing endothelial dysfunction [32].

\section{Arterial Stiffness and its Evolution as an Independent Predictor of Cardiovascular Risk}

The degree of arterial stiffness provoked by arteriosclerosis generates a faster pressure wave through a more rigid conduit. Thus, the degree of stiffness (or disease of the media, or arteriosclerosis) can be measured using pulse wave velocity, considered as the gold standard measure [33]. PWV has been accumulating evidence as an intermediate cardiovascular risk marker, after initial observations by Avolio et al. in China [34, 35].

Its independent power to predict cardiovascular disease was first determined in high-risk groups (chronic kidney disease, hypertension, diabetes) [36-39] and finally in the general population or in apparently healthy individuals [40-42].

For each increase in PWV of $1 \mathrm{~m} / \mathrm{s}$ the risk of cardiovascular events or all-cause mortality increases by 14 to $15 \%$ [43]; or if one prefers, by each increase in 1 standard deviation (SD) of PWV, the risk of cardiovascular events increased by $30 \%$ [4] - this most recent meta-analysis had yet another particular detail: it associated PWV with an increased risk of stroke, especially in younger age classes.

In a recent consensus document endorsed by the European Society of Cardiology and the Artery Society [44], carotid-femoral PWV has been established as a biomarker that is highly sensitive for identification of subjects with different phenotypes and with clinical relevance for therapy guidance, 
as well as bearing risk prediction improvement; nowadays it fulfills 8 of the 9 criteria established by the two societies to be considered a valuable biomarker (by use of an upgraded classification from Hlatky and colleagues [45]), and it gathers a "IIa" recommendation (with an "A" level of evidence) for use in risk stratification [44] - one of the three new biomarkers that achieve this classification. It is important to remember that the 2013 ESH-ESC Guidelines for the management of arterial hypertension, graded this recommendation as "IIa" (PWV should be considered to detect arterial stiffening) with a "B" level of evidence [46].

The definition of reference values for pulse wave velocity, according to age groups (in the "healthy population") and according to age and blood pressure class (in the "reference population" - corresponding to subjects that either smoke, have high-normal blood pressure or untreated hypertension or dyslipidemia) [25], has established a grid against which one can now compare the dimension of arterial damage expected for a given age in predetermined circumstances, identifying subjects that are off the grid as evidencing an abnormal vascular ageing process.

\section{THE CONCEPT AND PROPOSED DEFINITIONS OF EARLY VASCULAR AGEING}

The EVA concept is a tool for early identification of subjects that could benefit the most from early primary prevention measures. It embraces the knowledge of all the physiopathology of arterial ageing described summarily in previous sections of this overview, as well as all the singular capability of risk prediction concerning CVD by PWV measurements (as a proxy of arterial stiffness or arteriosclerosis) to answer the following questions: do the large arteries of an individual exhibit signs of accelerated or unsuccessful ageing? Does this abnormal rate of arterial ageing place this individual at a risk level for cardiovascular event that would imply early clinical intervention?

\subsection{Current Methods Used to Identify EVA Subjects}

The palpable definition of a subject exhibiting EVA is a work in development. For the time being it has relied mainly on three different methods: 1) to use the normal distribution of PWV values in a population, and define as EVA subjects those who place themselves 2 standard deviations above the mean PWV value [47]; 2) to transform all PWV values of the population into z-scores and classify as EVA those subjects who present $\mathrm{z}$-score above the $95^{\text {th }}$ percentile [47]; or 3) the last method is similar in concept to the previous two presented, but it uses as reference for normality those values published in the European Reference Values Collaboration [25]: EVA subjects are those who have a PWV value 2 SD above the "normal" PWV expected for age (according to the European Reference Values Collaboration) or whose z-score is above the $97.5^{\text {th }}$ percentile (using the age attributed "normal" PWV value as comparator) [48].

These are still probably incomplete and rough methods to establish those who have EVA. Will subjects having PWV within the $90^{\text {th }}$ percentile of the distribution be free of concern regarding their future cardiovascular health? Are there any other biomarkers that can be added to these definitions or that can complement them? For this matter, much data has been published concerning carotid Intima Media Thickness (cIMT), and it makes sense that we add a direct observation of the arterial wall to also identify those whose medial dimension has enlarged. Several studies and meta-analysis have supported this premise, evidencing that cIMT increases cardiovascular risk prediction beyond established risk algorithms, as well as it presents a modest risk reclassification power [49-51]; in one other meta-analysis however, the added value of measuring cIMT above the Framingham risk score was minor and precluded its clinical use [52]. However, the inclusion of this biomarker in the identification of EVA subjects has already spurred interest in the scientific community [53], and the fact that recent European reference values of cIMT, obtained with high resolution echo-tracking, have been published is obviously a facilitator of its transition to clinical use [54]. Results from the CARDIA, the Amsterdam Growth and Health Longitudinal and the Bogalusa studies are seriously encouraging in this domain as they evidence a correlation of early exposure to cardiovascular risk factors and concurrent changes in cIMT $[55,56]$, as well as development of cognitive dysfunction [57].

Should EVA subjects be considered as such if one of the characteristics (PWV or cIMT) present higher than expected (above the $97.5^{\text {th }}$ percentile) values for healthy individuals of the same age group, using the European Reference Values Collaboration as comparators? Or should they present both characteristics simultaneously? These are questions to be answered in the future.

\section{WHO, HOW AND WHEN TO SCREEN? THE EVA- HAS CONSTELLATION}

\subsection{Who}

Even if the measurement devices of PWV are easy to use, their availability is not yet disseminated in clinical practice. The European Society of Hypertension / European Society of Cardiology guidelines already include PWV as a part of target organ damage evaluation recommended for all hypertensive subjects [46], which constitutes a clear opportunity to evaluate EVA, whether target organ damage is absent (i.e., if $\mathrm{PWV}<10 \mathrm{~m} / \mathrm{sec}$ ), or not. Still, many other individuals with cardiovascular risk factors, or chronic inflammatory diseases should be screened for EVA [16]; as such, individuals with a positive familial history of premature cardiovascular disease, obstructive sleep apnea, chronic obstructive pulmonary disease, chronic inflammatory rheumatologic and immunologic conditions [58, 59], diabetes mellitus, dyslipidemia (especially familial hereditary forms), smoking, or chronic kidney disease, amongst others, should have their arterial stiffness evaluated.

\subsection{The EVA-HAS Constellation}

Attention has also been devoted to hemodynamic signs that appear as a consequence of arterial stiffness, and that could be incorporated in what one could denominate as an early vascular ageing - hemodynamic ageing syndrome (EVA - HAS) [31]; postural hypotension, elevated blood pressure variability [60], and isolated systolic hypertension could, thus, be also signals that when detected could lead the 
clinician to evaluate arterial stiffness and evidence of EVA. It can be suggested that morphological changes in the arterial wall constitute the fundament for EVA, but that the hemodynamic changes that occur as a consequence of the morphological changes can be regarded as HAS.

\subsection{When}

Scheduling an arterial stiffness evaluation should be prompt during the first evaluation of every hypertensive individual, or during the first evaluation of any of the individuals showing the above mentioned conditions or signs. A special attention should still be addressed to subjects that, during their first clinical evaluation, are classified by risk algorithms as having moderate added risk, as these are the ones most benefiting from reclassification into higher risk classes and concurrent treatment intensification [61].

\subsection{How}

The conditions of correct measurement of PWV have been extensively reviewed in several documents [33] and recently in a consensus document [62]. Three sets of recommendations are particularly noteworthy: 1) the premeasurement conditions to observe - fasting (including no caffeinated beverages), no smoking, a 10 minute rest before examination in a quiet room and in the supine position; 2) the direct carotid - femoral distance should be measured in a straight line, and the obtained PWV with this distance should be multiplied by 0.8 to obtain the final PWV value; 3 ) at least two measurements that do not differ more than $0.5 \mathrm{~m} / \mathrm{s}$ should be taken for each individual. Conditions precluding the inability to use the technique should be taken into consideration [62]. Another aspect to consider pertains to the standardization of PWV obtained with different devices and using different peripheral blood pressure measurements to calibrate the pulse wave form (systolic blood pressure + diastolic blood pressure vs. mean blood pressure). This issue has been fully addressed elsewhere [25]

\section{PREVALENCE OF EARLY VASCULAR AGEING IN THE GENERAL POPULATION}

Till recently, no estimate of the prevalence of EVA had been published. In a cohort study, including a randomly selected representative sample of two adjacent cities in the north of Portugal (Guimarães and Vizela), a thorough phenotypic evaluation of subjects concerning cardiovascular risk was performed. In a two-visit screening study, collection of data regarding clinical history, extensive biochemical workup of blood and urine, measurement of central hemodynamic parameters and cognitive function was performed in three thousand and thirty eight subjects. A full description of the followed methodology has been reported elsewhere [63].

Of the 2542 subjects who completed the observation plan, we registered a mean age of 45.5 years and a $55 \%$ prevalence of females. After transforming PWV values into Z-scores we compared the PWV values of our subjects with what would be the expected PWV value for someone his/her age in the normal ("healthy") population of the European Reference Values Collaboration. Using this method we ob- served that $12.5 \%$ of the population showed signs of EVA. The prevalence of EVA was mainly occurring in the age classes below 50 years, and the most striking observation was that $26.1 \%$ of individuals under 30 years of age presented its features, according to this definition, with a significantly increased prevalence in young males [48]. As we previously discussed, a cut-off value is always arbitrary and the fact is that cardiovascular risk has an increasing continuous relationship with the increase of PWV values. Thus, also worrisome was the finding, in this same study, that approximately $35 \%$ of individuals aged less than 40 years present a PWV value that is above the $90^{\text {th }}$ percentile of PWV expected for his/her age according to the European Reference Values Collaboration [25]. These data are of importance when we consider that the two studied adjacent cities are located in the region of Western Europe with the highest stroke rate incidence $[64,65]$.

Shortcomings of this observational study should be acknowledged, mainly due to the fact that only one PWV measurement was performed in each subject, and that a historical bias can have been introduced in the interpretation of results, as some of the studied cohorts that are included in the European Reference Values Collaboration have been examined 20 years ago [48].

Even if, so far, no other study has determined the prevalence of EVA, it is noteworthy to analyze two different aspects that could offer partial explanation for these results: a) following a political revolution approximately 40 years ago, Portugal has experienced a significant change in both living / nutritional habits and social behavior; the truth to the matter is that nowadays, statistics show high levels of childhood and teenager overweight and obesity as well as physical inactivity and elevated blood pressure levels [66, 67] - for subjects below 40 years of age, for instance, blood pressure levels are significantly above the minimum theoretical exposure risk values for the development of cardiovascular disease [68]; b) in several studies looking into another vascular biomarker (cIMT), an inverse relationship has been found between the maintenance of ideal cardiovascular health behaviors in childhood and measured values of cIMT [69-71].

On a totally different (but related) topic, one must consider the use of EVA in different fields of clinical cardiovascular disease prevention. For example, in a case- control study involving 223 catheter laboratory workers, a significant association was found between high risk exposure to radiation, increased cIMT and shorter telomere length [72]. Thus, radiation exposure is another factor that could to be involved in accelerated biological ageing. This opens new population targets to evaluate for EVA, i.e. occupationally, circumstantially or warfare exposed to radiation.

\section{THERAPEUTIC IMPLICATIONS: DE-STIFFENING THE ARTERIAL WALL}

The role of arterial stiffness as a surrogate marker for cardiovascular disease, with significant implications for the risk of its development has been well established and demonstrated both herein and in the extensive research work presented by different research teams around the world. The issue of treatment of arterial stiffness as a therapeutic target 
is still subject to debate, with clear ramifications to the rational of clinical approach of the patient with EVA.

The pharmacologic treatment options for subjects with EVA, according to the existing evidence, are mainly dependent of the fact that the same individual has hypertension or not. In fact, using anti-hypertensive drug therapy will, in parallel, reduce arterial stiffness by decreasing the stiffness proportion corresponding to the pressure load of collagen fibers in the arterial wall, by increased blood pressure. With current existing evidence, (and due to the lack of trials showing that PWV can itself be a therapeutic target with proven cardiovascular benefit) these drugs can only be used in hypertensive subjects.

Still, no mistake should be made that, in the EVA subjects with no clinical indication to use anti-hypertensive treatment, other ways of reducing blood pressure (and thus obtain stiffness reduction through the above mentioned mechanism) should be recommended in so far as this blood pressure reduction would not harm the individual, taking into account his/her particular clinical features (Tables $1 \& 2$ ); these non-pharmacological blood pressure reductions should be achieved through reduction of salt consumption [73], appropriate regular physical activity, weight loss and reduction of alcohol consumption $[74,75]$.
Other therapeutic interventions for the subject with EVA include pragmatic and strict attitudes on: a) smoking cessation; b) detection and control of traditional and nontraditional cardiovascular risk factors (diabetes, dyslipidemia, abdominal obesity); c) detection and reversion of the metabolic syndrome [17]; d) appropriate primary prevention measures and treatment targets, in accordance with the global cardiovascular risk class [74]; and e) control of inflammatory disease states, reduction of oxidative stress and improvement of endothelial dysfunction. One capital issue in these subjects is close follow-up and constant reassessment of interventions.

\subsection{Arterial Stiffness and EVA in Hypertensive Patients}

For the EVA subject with hypertension, other pharmacologic therapeutic options can be included in the treatment strategy of the patient, in accordance with the existing evidence. Two particular aspects should be considered: 1) all the above mentioned treatment strategies, which are appropriate for the non-hypertensive EVA subject, are still indicated in the EVA hypertensive patient; 2) The fundamental cornerstone of treatment is blood pressure control - even if one must not put aside the role in arterial remodeling (and arterial stiffness reduction) achieved by a long term use of

Table 1. Therapeutic interventions in subjects with Early Vascular Aging.

\begin{tabular}{|c|c|}
\hline \multirow{5}{*}{$\begin{array}{c}\text { Non- } \\
\text { Hypertensive } \\
\text { Subjects }\end{array}$} & $\begin{array}{l}\text { Obtain non-pharmacologic and clinically sustainable reductions of BP by reducing salt consumption, appropriate regular physical } \\
\text { activity, weight loss and reduction of alcohol consumption }\end{array}$ \\
\hline & Smoking cessation \\
\hline & Control of traditional and non-traditional cardiovascular risk factors (hyperglycemia/diabetes, dyslipidemia, abdominal obesity) \\
\hline & Reversion of the metabolic syndrome \\
\hline & Control of chronic inflammatory disease states \\
\hline \multirow{3}{*}{$\begin{array}{c}\text { Hypertensive } \\
\text { Subjects }\end{array}$} & Institute equally all the non-pharmacologic / healthy lifesytle measures proposed for non-hypertensive subjects \\
\hline & Control Blood Pressure (independently of drug class used) \\
\hline & $\begin{array}{l}\text { If possible, use preferentially ACE inhibitors, ARB's, aldosterone antagonists, calcium channel blockers and/or vasodilating beta- } \\
\text { blockers. Inhibitors of the renin - angiotensin system and calcium channel blockers (either alone or in combination, should be preferred) }\end{array}$ \\
\hline
\end{tabular}

Table 2. Summary about EVA.

\begin{tabular}{|c|r|}
\hline $\mathbf{1 .}$ & EVA is an evolving concept aiming at earlier identification of subjects at increased risk of CVD \\
\hline $\mathbf{2 .}$ & $\begin{array}{r}\text { The BP/Arterial Stiffness paradox: BP is a main determinant of Arterial stiffness; still evidence shows that these variables have a divergent } \\
\text { evolution with age, according to gender, making it clear that they bear different prognostic information in terms of CVD risk }\end{array}$ \\
\hline $\mathbf{3 .}$ & Arterial Stiffness is an independent predictor of CVD, both in high-risk CV subjects and at the general population level \\
\hline $\mathbf{4 .}$ & $\begin{array}{r}\text { Screening for EVA should be done in; hypertensive patients (with no TOD); individuals with CVRF or chronic inflammatory diseases; subjects } \\
\text { with moderate risk for the development of CVD }\end{array}$ \\
\hline $\mathbf{5 .}$ & $\begin{array}{r}\text { In one population based study, the prevalence of EVA was 12.5\%; one out of every for subjects bellow } \\
30 \text { years of age presented with this characteristic }\end{array}$ \\
\hline $\mathbf{6 .}$ & $\begin{array}{r}\text { Therapeutic implications - there are two distinct sets of recommendations for therapeutic attitudes in subjects with EVA, } \\
\text { considering their hypertension status (please see Table 1) }\end{array}$ \\
\hline
\end{tabular}


antihypertensive drugs, beyond blood pressure reduction [76].

Having said this, particular drugs may have beneficial effect on arterial stiffness reversion, other than blood pressure control. A particular attention should be paid to subjects with already low diastolic blood pressure but high pulse pressure levels, in whom aggressive decrease of blood pressure could compromise diastolic perfusion - nitrates and nitric oxide donors, acting more selectively in large arteries are options to consider and closely study for this purpose [77]. In a seminal work, Guérin and colleagues followed 150 individuals with end-stage renal disease for approximately 52 months, and showed that those who responded to antihypertensive treatment with blood pressure lowering and pulse wave velocity reduction were the ones with the better survival prognosis, as opposed to those who, having responded to blood pressure reduction, did not register similar PWV reduction [78].

Much information has been published regarding blockers of the renin-angiotensin-aldosterone system (RAAS) as cornerstone drugs to use whenever arterial stiffness reversibility is a consideration during treatment, independently of $\mathrm{BP}$ reduction [79-82].

A sub-study of the PEACE trial [83], compared the long term use of trandolapril vs. placebo in 300 subjects with stable coronary heart disease and left ventricular ejection fraction $>40 \%$, to observe that those subjects under trandrolapril treatment had lower PWV values at the end of the study, even after adjustment for the decrease in mean arterial pressure (also higher in the trandolapril arm). The authors concluded that an effect of PWV reduction could be associated to the use of ACE inhibition, beyond blood pressure lowering [83].

A post-hoc analysis of the EXPLOR trial [84], a prospective, randomized, parallel groups multicenter trial with a PROBE design, where 393 subjects with essential hypertension were randomized to treatment with valsartan (plus amlodipine at week 8) or atenolol (plus amlodipine at week 8), has shown that at week $24,47 \%$ of the reduction in PWV (after adjustment for blood pressure and heart rate) in the valsartan arm was independent of changes in mean blood pressure. In a different prospective, randomized, open-label, blinded end point (PROBE) study, 207 hypertensive patients were treated with olmesartan for 24 weeks (with either azelnidipine or hydrochlorothiazide added on at week 12), with the olmesartan/azelnidipine arm showing significant superiority in decreasing PWV, beyond achieved blood pressure reduction [85].

A meta-analysis of individual data performed by Ong et $a l$., showed that, in 294 previously untreated mild to moderate hypertensives, arterial stiffness could be improved by anti-hypertensive treatment beyond blood pressure reduction, particularly pointing out the efficacy of angiotensin converting enzyme inhibitors (ACEi), angiotensin receptor blockers (ARB), calcium channel antagonists (CCA) and beta-receptor blockers (B-block) - the later in long term trials. More important in this meta-analysis was the observation of a dissociation of PWV and blood pressure evolution and response to treatment with time, following blood pressure control [86]. The data on ACEI ability to reverse arterial stiffness has been partially reinforced by another meta-analyzes and meta-regression of randomized control trials, including 23 studies; yet, ACEI showed no clear superiority over other drugs antihypertensive drugs in reversing PWV, but a significant benefit in reducing augmentation index (Aix) $[87,88]$.

\section{CONCLUSION AND FUTURE DIRECTIONS}

Even if much evidence has been accumulated concerning the important independent prognostic value of c-f PWV for the development of CVD, so far no single published study has been structured to show evidence that a treatment strategy aimed at reducing arterial stiffness could be beneficial in terms of cardiovascular disease prevention and cardiovascular risk reduction. New study strategies have already been devised for this purpose, and the ongoing SPARTE trial [89] should bring new insights to this issue.

The EVA concept will evolve, and new definitions including other biomarkers (e.g. cIMT) could facilitate its translation to clinical use as a concept embedded in primordial prevention of cardiovascular disease.

\section{CONFLICTS OF INTEREST AND SOURCE OF FUNDING}

No conflicts of interest to declare; funding by the Life and Health Research Institute, Minho University

\section{ACKNOWLEDGEMENTS}

Declared none.

\section{REFERENCES}

[1] Nilsson PM. Early vascular aging (EVA): consequences and prevention. Vasc Health Risk Manag 2008; 4(3): 547-52.

[2] Nilsson PM, Boutouyrie P, Laurent S. Vascular aging: A tale of EVA and ADAM in cardiovascular risk assessment and prevention. Hypertension 2009; 54(1): 3-10.

[3] Nilsson PM, Boutouyrie P, Cunha P, et al. Early vascular ageing in translation: from laboratory investigations to clinical applications in cardiovascular prevention. J Hypertens 2013; 31(8): 1517-26.

[4] Ben-Shlomo Y, Spears M, Boustred C, et al. Aortic pulse wave velocity improves cardiovascular event prediction: an individual participant meta-analysis of prospective observational data from 17,635 subjects. J Am Coll Cardiol 2014; 63(7): 636-46.

[5] Nilsson PM, Lurbe E, Laurent S. The early life origins of vascular ageing and cardiovascular risk: the EVA syndrome. J Hypertens 2008; 26(6): 1049-57.

[6] Laurent S. Defining vascular aging and cardiovascular risk. J Hypertens 2012; 30: S3-8.

[7] Nilsson PM, Boutouyrie P, Cunha P, et al. Early vascular ageing in translation: from laboratory investigations to clinical applications in cardiovascular prevention. J Hypertens 2013; 31(8): 1517-26.

[8] O'Rourke MF, Safar ME, Dzau V. The Cardiovascular Continuum extended: aging effects on the aorta and microvasculature. Vasc Med 2010; 15(6): 461-8.

[9] O'Rourke MF, Hashimoto J. Mechanical factors in arterial aging: a clinical perspective. J Am Coll Cardiol 2007; 50(1): 1-13.

[10] Redheuil A, Yu WC, Wu CO, et al. Reduced ascending aortic strain and distensibility: earliest manifestations of vascular aging in humans. Hypertension 2010; 55(2): 319-26.

[11] Greenwald SE. Ageing of the conduit arteries. J Pathol 2007; 211(2): 157-72.

[12] Nichols WW. Clinical measurement of arterial stiffness obtained from noninvasive pressure waveforms. Am J Hypertens 2005; $18(1$ Pt 2): 3S-10S. 
[13] Kunz J. Initial lesions of vascular aging disease (arteriosclerosis). Gerontology 2000; 46(6): 295-9.

[14] McEniery CM, Wallace S, Mackenzie IS, et al. Endothelial function is associated with pulse pressure, pulse wave velocity, and augmentation index in healthy humans. Hypertension 2006; 48(4): 602-8.

[15] Safar ME, Balkau B, Lange C, et al. Hypertension and vascular dynamics in men and women with metabolic syndrome. J Am Coll Cardiol 2013; 61(1): 12-9.

[16] van Bussel BC, Schouten F, Henry RM, et al. Endothelial dysfunction and low-grade inflammation are associated with greater arterial stiffness over a 6-year period. Hypertension 2011; 58(4): 588-95.

[17] Scuteri A, Cunha PG, Rosei EA, et al. Arterial stiffness and influences of the metabolic syndrome: a cross-countries study. Atherosclerosis 2014; 233(2): 654-60.

[18] Gottsater M, Ostling G, Persson M, Engstrom G, Melander O, Nilsson PM. Non-hemodynamic predictors of arterial stiffness after 17 years of follow-up: the Malmo Diet and Cancer study. J Hypertens 2015 ; 33(5): 957-65.

[19] Jeanclos E, Schork NJ, Kyvik KO, Kimura M, Skurnick JH, Aviv A. Telomere length inversely correlates with pulse pressure and is highly familial. Hypertension 2000; 36(2): 195-200.

[20] O'Rourke MF. Arterial aging: pathophysiological principles. Vasc Med 2007; 12(4): 329-41.

[21] Muiesan ML, Salvetti M, Rizzoni D, et al. Pulsatile hemodynamics and microcirculation: evidence for a close relationship in hypertensive patients. Hypertension 2013; 61(1): 130-6.

[22] Laurent S, Boutouyrie P. The structural factor of hypertension: large and small artery alterations. Circ Res 2015; 116(6): 1007-21.

[23] Cunha PG, Olsen MH. Vascular aging and cardiovascular disease. In: Nilsson PM, Olsen MH, Laurent S, eds. Early Vascular Aging (EVA): New directions in cardiovascular protection. London: Elsevier; 2015. p. 261 - 71.

[24] Nichols WW, Denardo SJ, Wilkinson IB, McEniery CM, Cockcroft J, O'Rourke MF. Effects of arterial stiffness, pulse wave velocity, and wave reflections on the central aortic pressure waveform. J Clin Hypertens (Greenwich) 2008; 10(4): 295-303.

[25] Reference Values for Arterial Stiffness' Collaboration. Determinants of pulse wave velocity in healthy people and in the presence of cardiovascular risk factors: 'establishing normal and reference values'. Eur Heart J 2010; 31(19): 2338-50.

[26] McEniery CM, Yasmin, Hall IR, Qasem A, Wilkinson IB, Cockcroft JR. Normal vascular aging: differential effects on wave reflection and aortic pulse wave velocity: the Anglo-Cardiff Collaborative Trial (ACCT). J Am Coll Cardiol 2005; 46(9): 1753-60.

[27] AlGhatrif M, Strait JB, Morrell CH, et al. Longitudinal trajectories of arterial stiffness and the role of blood pressure: the Baltimore Longitudinal Study of Aging. Hypertension 2013; 62(5): 934-41.

[28] Kaess BM, Rong J, Larson MG, et al. Aortic stiffness, blood pressure progression, and incident hypertension. JAMA 2012; 308(9): 875-81.

[29] Najjar SS, Scuteri A, Shetty V, et al. Pulse wave velocity is an independent predictor of the longitudinal increase in systolic blood pressure and of incident hypertension in the Baltimore Longitudinal Study of Aging. J Am Coll Cardiol 2008; 51(14): 1377-83.

[30] Scuteri A, Morrell CH, Orru M, et al. Longitudinal perspective on the conundrum of central arterial stiffness, blood pressure, and aging. Hypertension 2014; 64(6): 1219-27.

[31] Nilsson PM. Hemodynamic aging as the consequence of structural changes associated with early vascular aging (EVA). Aging Dis 2014; 5(2): 109-13.

[32] Sun Z. Aging, arterial stiffness, and hypertension. Hypertension 2015; 65(2): 252-6.

[33] Laurent S, Cockcroft J, Van Bortel L, et al. Expert consensus document on arterial stiffness: methodological issues and clinical applications. Eur Heart J 2006; 27(21): 2588-605.

[34] Avolio AP, Deng FQ, Li WQ, et al. Effects of aging on arterial distensibility in populations with high and low prevalence of hypertension: comparison between urban and rural communities in China. Circulation 1985; 71(2): 202-10.

[35] Avolio AP, Chen SG, Wang RP, Zhang CL, Li MF, O'Rourke MF. Effects of aging on changing arterial compliance and left ventricular load in a northern Chinese urban community. Circulation 1983; 68(1): 50-8.
[36] Blacher J, Pannier B, Guerin AP, Marchais SJ, Safar ME, London GM. Carotid arterial stiffness as a predictor of cardiovascular and all-cause mortality in end-stage renal disease. Hypertension 1998; 32(3): 570-4.

[37] Laurent S, Boutouyrie P, Asmar R, et al. Aortic stiffness is an independent predictor of all-cause and cardiovascular mortality in hypertensive patients. Hypertension 2001; 37(5): 1236-41.

[38] Boutouyrie P, Tropeano AI, Asmar R, et al. Aortic stiffness is an independent predictor of primary coronary events in hypertensive patients: a longitudinal study. Hypertension 2002; 39(1): 10-5.

[39] Laurent S, Katsahian S, Fassot C, et al. Aortic stiffness is an independent predictor of fatal stroke in essential hypertension. Stroke 2003; 34(5): 1203-6.

[40] Willum-Hansen T, Staessen JA, Torp-Pedersen C, et al. Prognostic value of aortic pulse wave velocity as index of arterial stiffness in the general population. Circulation 2006; 113(5): 664-70.

[41] Mattace-Raso FU, van der Cammen TJ, Hofman A, et al. Arterial stiffness and risk of coronary heart disease and stroke: the Rotterdam Study. Circulation 2006; 113(5): 657-63.

[42] Mitchell GF, Hwang SJ, Vasan RS, et al. Arterial stiffness and cardiovascular events: the Framingham Heart Study. Circulation 2010; 121(4): 505-11.

[43] Vlachopoulos C, Aznaouridis K, Stefanadis C. Prediction of cardiovascular events and all-cause mortality with arterial stiffness: a systematic review and meta-analysis. J Am Coll Cardiol 2010; 55(13): 1318-27.

[44] Vlachopoulos C, Xaplanteris P, Aboyans V, et al. The role of vascular biomarkers for primary and secondary prevention. A position paper from the European Society of Cardiology Working Group on peripheral circulation: Endorsed by the Association for Research into Arterial Structure and Physiology (ARTERY) Society. Atherosclerosis 2015; 241(2): 507-32.

[45] Hlatky MA, Greenland P, Arnett DK, et al. Criteria for evaluation of novel markers of cardiovascular risk: a scientific statement from the American Heart Association. Circulation 2009; 119(17): 240816.

[46] Mancia G, Fagard R, Narkiewicz K, et al. 2013 ESH/ESC guidelines for the management of arterial hypertension: the Task Force for the Management of Arterial Hypertension of the European Society of Hypertension (ESH) and of the European Society of Cardiology (ESC). Eur Heart J 2013; 34(28): 2159-219.

[47] Kotsis V, Stabouli S, Karafillis I, Nilsson P. Early vascular aging and the role of central blood pressure. J Hypertens 2011; 29(10): 1847-53.

[48] Cunha PG, Cotter J, Oliveira P, et al. Pulse wave velocity distribution in a cohort study: from arterial stiffness to early vascular aging. J Hypertens 2015; 33(7): 1438-45.

[49] Lorenz MW, Markus HS, Bots ML, Rosvall M, Sitzer M. Prediction of clinical cardiovascular events with carotid intima-media thickness: a systematic review and meta-analysis. Circulation 2007; 115(4): 459-67.

[50] Lorenz MW, Polak JF, Kavousi M, et al. Carotid intima-media thickness progression to predict cardiovascular events in the general population (the PROG-IMT collaborative project): a metaanalysis of individual participant data. Lancet 2012; 379(9831): 2053-62.

[51] Polak JF, Szklo M, Kronmal RA, et al. The value of carotid artery plaque and intima-media thickness for incident cardiovascular disease: the multi-ethnic study of atherosclerosis. J Am Heart Assoc 2013; 2(2): e000087.

[52] Den Ruijter HM, Peters SA, Anderson TJ, et al. Common carotid intima-media thickness measurements in cardiovascular risk prediction: a meta-analysis. JAMA 2012; 308(8): 796-803.

[53] Maloberti A, Meani P, Varrenti M, et al. Structural and functional abnormalities of carotid artery and their relation with EVA phenomenon. High Blood Press Cardiovasc Prev 2015; 22(4): 373-9.

[54] Engelen L, Ferreira I, Stehouwer CD, Boutouyrie P, Laurent S. Reference intervals for common carotid intima-media thickness measured with echotracking: relation with risk factors. Eur Heart J 2013; 34(30): 2368-80.

[55] Bhuiyan AR, Srinivasan SR, Chen W, Paul TK, Berenson GS. Correlates of vascular structure and function measures in asymptomatic young adults: the Bogalusa Heart Study. Atherosclerosis 2006; 189(1): 1-7. 
[56] Ferreira I, van de Laar RJ, Prins MH, Twisk JW, Stehouwer CD. Carotid stiffness in young adults: a life-course analysis of its early determinants: the Amsterdam Growth and Health Longitudinal Study. Hypertension 2012; 59(1): 54-61.

[57] Zeki Al Hazzouri A, Vittinghoff E, Sidney S, Reis JP, Jacobs DR, Jr., Yaffe K. Intima-media thickness and cognitive function in stroke-free middle-aged adults: Findings from the coronary artery risk development in young adults study. Stroke 2015; 46(8): 2190-6.

[58] Santos MJ, Carmona-Fernandes D, Canhao H, Canas da Silva J, Fonseca JE, Gil V. Early vascular alterations in SLE and RA patients--a step towards understanding the associated cardiovascular risk. PloS One 2012; 7(9): e44668.

[59] Peters MJ, Symmons DP, McCarey D, et al. EULAR evidencebased recommendations for cardiovascular risk management in patients with rheumatoid arthritis and other forms of inflammatory arthritis. Ann Rheum Dis 2010; 69(2): 325-31.

[60] Schillaci G, Bilo G, Pucci G, et al. Relationship between short-term blood pressure variability and large-artery stiffness in human hypertension: findings from 2 large databases. Hypertension 2012; 60(2): 369-77.

[61] Sehestedt T, Jeppesen J, Hansen TW, et al. Risk prediction is improved by adding markers of subclinical organ damage to SCORE. Eur Heart J 2010; 31(7): 883-91.

[62] Van Bortel LM, Laurent S, Boutouyrie P, et al. Expert consensus document on the measurement of aortic stiffness in daily practice using carotid-femoral pulse wave velocity. J Hypertens 2012; 30(3): 445-8.

[63] Cunha PG, Cotter J, Oliveira P, Vila I, Sousa N. The rationale/design of the guimaraes/vizela study: a multimodal populationbased cohort study to determine global cardiovascular risk and disease. J Investig Med 2014; 62(5): 813-20.

[64] Correia M, Silva MR, Matos I, et al. Prospective community-based study of stroke in Northern Portugal: incidence and case fatality in rural and urban populations. Stroke 2004; 35(9): 2048-53.

[65] Nichols M, Townsend N, Luengo-Fernandez R, Leal J, Gray A, Scarborough P, Rayner M. European Cardiovascular Disease Statistics 2012. European Heart Network, Brussels: (2012).

[66] Wijnhoven TM, van Raaij JM, Sjoberg A, et al. WHO European Childhood Obesity Surveillance Initiative: School nutrition environment and body mass index in primary schools. Int J Environ Res Public Health 2014; 11(11): 11261-85.

[67] Organisation W-WH. Country profiles on nutrition, physical activity and obesity in the 28 European Union Member States of the WHO European Region. Europe ROf; 2013 ISBN 9789289050098.

[68] Cunha PG, Cotter J, Oliveira P, Vila I, Sousa N. An epidemiological study determining blood pressure in a Portuguese cohort: the Guimaraes/Vizela study. J Hum Hypertens 2015; 29(3): 190-7.

[69] Oikonen M, Laitinen TT, Magnussen CG, et al. Ideal cardiovascular health in young adult populations from the United States, Finland, and Australia and its association with cIMT: the International Childhood Cardiovascular Cohort Consortium. J Am Heart Assoc 2013; 2(3): e000244.

[70] Ferreira I, Beijers HJ, Schouten F, Smulders YM, Twisk JW, Stehouwer CD. Clustering of metabolic syndrome traits is associated with maladaptive carotid remodeling and stiffening: a 6-year longitudinal study. Hypertension 2012; 60(2): 542-9.

[71] Laitinen TT, Pahkala K, Magnussen CG, et al. Ideal cardiovascular health in childhood and cardiometabolic outcomes in adulthood: the Cardiovascular Risk in Young Finns Study. Circulation 2012; 125(16): 1971-8.

[72] Andreassi MG, Piccaluga E, Gargani L, et al. Subclinical carotid atherosclerosis and early vascular aging from long-term low-dose ionizing radiation exposure: a genetic, telomere, and vascular ultrasound study in cardiac catheterization laboratory staff. JACC Cardiovasc Interv 2015; 8(4): 616-27.

[73] He FJ, Li J, Macgregor GA. Effect of longer term modest salt reduction on blood pressure: Cochrane systematic review and metaanalysis of randomised trials. BMJ 2013; 346: f1325.

[74] Perk J, De Backer G, Gohlke H, et al. European Guidelines on cardiovascular disease prevention in clinical practice (version 2012). The Fifth Joint Task Force of the European Society of Cardiology and Other Societies on Cardiovascular Disease Prevention in Clinical Practice (constituted by representatives of nine societies and by invited experts). Developed with the special contribution of the European Association for Cardiovascular Prevention \& Rehabilitation (EACPR). Eur Heart J 2012; 33(13): 1635-701.

[75] Calhoun DA. Resistant or difficult-to-treat hypertension. J Clin Hypertens (Greenwich) 2006; 8(3): 181-6.

[76] Ait-Oufella H, Collin C, Bozec E, et al. Long-term reduction in aortic stiffness: a 5.3-year follow-up in routine clinical practice. $\mathrm{J}$ Hypertens 2010; 28(11): 2336-41.

[77] Van Bortel LM, De Backer T, De Buyzere M. How to treat arterial stiffness beyond blood pressure lowering? J Hypertens 2011; 29(6): 1051-3.

[78] Guerin AP, Blacher J, Pannier B, Marchais SJ, Safar ME, London GM. Impact of aortic stiffness attenuation on survival of patients in end-stage renal failure. Circulation 2001; 103(7): 987-92.

[79] Blacher J, Safar ME. Large-artery stiffness, hypertension and cardiovascular risk in older patients. Nat Clin Pract Cardiovasc Med 2005; 2(9): 450-5.

[80] Van Bortel LM, Struijker-Boudier HA, Safar ME. Pulse pressure, arterial stiffness, and drug treatment of hypertension. Hypertension 2001; 38(4): 914-21.

[81] Tropeano AI, Boutouyrie P, Pannier B, et al. Brachial pressureindependent reduction in carotid stiffness after long-term angiotensin-converting enzyme inhibition in diabetic hypertensives. Hypertension 2006; 48(1): 80-6.

[82] Laurent S, Boutouyrie P. Dose-dependent arterial destiffening and inward remodeling after olmesartan in hypertensives with metabolic syndrome. Hypertension 2014; 64(4): 709-16.

[83] Mitchell GF, Dunlap ME, Warnica W, et al. Long-term trandolapril treatment is associated with reduced aortic stiffness: the prevention of events with angiotensin-converting enzyme inhibition hemodynamic substudy. Hypertension 2007; 49(6): 1271-7.

[84] Boutouyrie P, Beaussier H, Achouba A, Laurent S. Destiffening effect of valsartan and atenolol: influence of heart rate and blood pressure. J Hypertens 2014; 32(1): 108-14.

[85] Matsui Y, Eguchi K, O'Rourke MF, et al. Differential effects between a calcium channel blocker and a diuretic when used in combination with angiotensin II receptor blocker on central aortic pressure in hypertensive patients. Hypertension 2009; 54(4): 71623 .

[86] Ong KT, Delerme S, Pannier B, et al. Aortic stiffness is reduced beyond blood pressure lowering by short-term and long-term antihypertensive treatment: a meta-analysis of individual data in 294 patients. J Hypertens 2011; 29(6): 1034-42.

[87] Shahin Y, Khan JA, Chetter I. Angiotensin converting enzyme inhibitors effect on arterial stiffness and wave reflections: a metaanalysis and meta-regression of randomised controlled trials. Atherosclerosis 2012; 221(1): 18-33.

[88] Boutouyrie P, Lacolley P, Briet M, et al. Pharmacological modulation of arterial stiffness. Drugs 2011; 71(13): 1689-701.

[89] Laurent S, Briet M, Boutouyrie P. Arterial stiffness as surrogate end point: needed clinical trials. Hypertension 2012; 60(2): 518-22. 